\title{
DESVENDANDO O CONSUMO RITUALÍSTICO DOS BAILES DE DEBUTANTE
}

\author{
Unveiling the ritualistic debutante balls consumption \\ Revelando el consumo ritual de bailes de debutante
}

\author{
Stephanie Duarte Estéban \\ Universidade de São Paulo, São Paulo, Brasil. \\ Advogada formada pela Universidade Estadual de Maringá. Mestrado em Administração pelo programa de \\ pós-graduação em Administração da Universidade Estadual de Maringá. Doutoranda em Administração pela \\ Faculdade de Economia, Administração e Contabilidade de Ribeirão Preto da Universidade de São Paulo. \\ E-mail: stephanieesteban@usp.br
}

\section{Olga Maria Coutinho Pépece}

\author{
Universidade Estadual de Maringá, Maringá, Brasil.
}

Graduada em Administração pela Universidade Estadual de Londrina. Mestrado e doutorado em Administração com ênfase em Comportamento do Consumidor pela Universidade Federal do Paraná. Professora adjunta do programa de pós-graduação em Administração da Universidade Estadual de Maringá.

E-mail: omcpepece@uem.br

\begin{abstract}
RESUMO Este estudo buscou identificar os pressupostos que compõem o baile de debutante, um consumo repleto de significados que movimenta grandes cifras econômicas e a respeito do qual a pesquisa sobre o consumidor carece de conhecimento. Para tanto, foi aplicada uma pesquisa de cunho qualitativo e exploratório. A coleta de dados se deu por meio de entrevistas semiestruturadas e, posteriormente, realizou-se a análise de conteúdo para interpretação dos dados. O estudo permitiu identificar que o baile de debutante na contemporaneidade tem como principal motivação a ostentação do poder aquisitivo da família da aniversariante e busca não mais um casamento para a jovem, mas aumentar suas redes de contatos.
\end{abstract}

PALAVRAS-CHAVE Ritual, Consumo, Comportamento do consumidor, Baile de debutante.

ABSTRACT This study sought to identify the assumptions that make the debutante's ball, a consumption that is full of meanings that drives large economic figures and its consumer research lacks knowledge. For that, a qualitative and exploratory research was applied, and the data collection was done through semi-structured interviews and, afterwards, content analysis was performed for the data interpretation. The study made possible to identify that the debutante's ball in contemporary times has as main motivation the ostentation of the family's purchasing power of the birthday girl, and seeks no longer a marriage for the debutante, but to increase her networks of contacts.

KEYWORDS Ritual, Consumption, Consumer behavior, Debutante ball.

RESUMEN Este estudio buscó identificar los presupuestos que componen el baile de debutante, consumo repleto de significados que mueve grandes cifras económicas y a respecto del cual la investigación sobre el consumidor carece de conocimiento. Para ello, se aplicó una investigación de carácter cualitativo y exploratorio, siendo que la recolección de datos se dio por medio de entrevistas semiestructuradas y, después, se realizó el análisis de contenido para interpretación de los datos. El estudio permitió identificar que el baile de debutante en la contemporaneidad tiene como principal motivación la ostentación del poder adquisitivo de la familia de la cumpleañera y busca no más un matrimonio para la joven, pero aumentar su red de contactos.

PALABRAS CLAVE Ritual, Consumo, Comportamiento del consumidor, Baile de debutante. 


\section{INTRODUÇÃO}

Quando se vê aquela garota, vestida com um lindo vestido, entrando no salão de mãos dadas com o pai para a valsa, não se imagina a quantidade de significados que estão sendo passados de geração a geração. Esse é o baile de debutante ou, como é mais conhecido no Brasil, a festa de 15 anos. Muitos dizem que não possui outro significado se não o de uma festa, mas por que ainda são gastas vultosas quantias na realização desse evento? A festa acontece sempre da mesma forma? O que motiva esse consumo? Essas são algumas das perguntas que inspiraram esta pesquisa.

O baile de debutante é caracterizado como consumo ritualístico de passagem. A construção ritual oferece grande potencial para interpretar muitos aspectos dos fenômenos de consumo. Isso se dá porque o ritual é um marco conceitual que oferece informações valiosas sobre as experiências de vida dos consumidores e os tipos de significados simbólicos que estes investem no uso de produtos de consumo (TETREAULT; KLEINE III, 1990).

Os rituais coletivos modernos de lazer e consumo, tais como eventos esportivos, festas e artes, têm papel de grande relevância para a compreensão da sociedade, já que neles é possível verificar a transferência de significado cultural para os bens (ROOK, 2007). Embora existam diversos consumos ritualísticos, como baile de debutante, casamento e formatura, entre outros repletos de significados e que movimentam grandes cifras econômicas (como se verá, a seguir, nos discursos dos profissionais), a pesquisa sobre o consumidor tem falhado em reconhecer esse amplo domínio comportamental (CUPOLIO; CASOTTI; CAMPOS, 2013).

Este estudo, portanto, pautou-se na análise do baile de debutante como consumo ritualístico. Para tanto, como objetivo geral, buscou-se identificar os componentes da definição de ritual na festa e seus significados a partir da percepção de profissionais envolvidos na realização de festas da cidade de Maringá-PR. Para atingir tal objetivo, foram levantados os pressupostos da definição de ritual (artefatos simbólicos, roteiro, papéis dos agentes, audiência e repetição) e os significados do consumo dos artefatos simbólicos presentes nos bailes de debutante.

A cidade de Maringá, localizada no interior do estado do Paraná, é de economia predominantemente agrícola e de prestação de serviços, tendo um perfil de população adulta de alto poder aquisitivo $(24,58 \%$ de famílias das classes socioeconômicas A e B) (GUILLEN, 2012) e bastante conservador em termos de consumo (TEIXEIRA, 2013). Já a população jovem segue as tendências internacionais de se casar próximo aos 30 anos (COLETO, 2009) ou, em alguns casos, de optar por não casar. Neste contexto, identificou-se que os bailes de debutante continuam bastante presentes no município, o que chamou a atenção das pesquisadoras para entender melhor este consumo na atualidade.

\section{SOCIEDADE, CULTURA E CONSUMO}

A sociedade contemporânea é constantemente ligada à ideia de consumo devido à relevância deste para fins simbólicos de diferenciação, atribuição de status, pertencimento e gratificação individual entre os grupos sociais (BARBOSA, 2010). Slater (2002, p. 148) afirma que o uso 
dos bens permite a organização das nossas relações sociais, classificando pessoas e eventos:

Com o uso dos bens, podemos construir e manter um universo social inteligível, uma vez que ao classificar, comparar e ordenar as coisas que temos e usamos, damos sentido e organizamos nossas relações sociais, classificando pessoas e eventos.

Trindade et al. (2011) dizem que o que ocorre então é uma dinâmica enunciativa da construção de sentidos, que se faz nos processos de transferência de significados da fabricação do produto à construção dos vínculos de sentidos nos contextos de consumo.

Sassatelli (2007) afirma que os produtos funcionam como um sistema de comunicação não verbal e são colocados em uso para marcar as fronteiras sociais e culturais. Bourdieu (1973) trata dessa questão das fronteiras dizendo que os consumidores fazem diferença entre bens, a fim de se distinguirem. "É válido dizer que o ato de consumir aproxima e/ou distancia pessoas, ainda mais quando elitiza (especifica, separa, determina) o procedimento efetivo de compra - o poder de adquirir" (GARCIA, 2009, p. 217).

Seguindo essa linha de raciocínio, Bourdieu (1973) menciona ainda que o consumo é essencial para a estratificação social e participa na consolidação dos vários campos da prática social. Para o autor, é possível distinguir indivíduos, grupos e classes sociais a partir da análise das associações entre diferentes grupos de agentes e suas preferências em termos de consumo. Outra forma de se distinguir os indivíduos é em função de três dimensões fundamentais de capital, que interagem entre si: capital econômico, capital social e capital cultural (STREHLAU, 2008).

O capital econômico de um indivíduo é constituído por seus rendimentos e bens negociáveis. Como exemplo, tem-se os dividendos de acionistas que possuem participações iguais de uma empresa. Já o capital social é um conjunto de recursos, atuais e potenciais, ligados à posse de uma rede de relações mais ou menos institucionalizadas de conhecimento e reconhecimento (STREHLAU, 2008), como alunos contemporâneos de um colégio.

O capital cultural é compreendido em três formas: incorporado, objetivo e institucionalizado. No estado incorporado, é ligado ao corpo e supõe uma inclusão. Assim, esse capital diz respeito à assimilação do aprendizado e, para isso, é necessário um investimento em termos de tempo pelo indivíduo, como quando se aprende a tocar piano. O capital cultural no estado objetivo tem qualidade somente na relação com o capital cultural incorporado, ou seja, é um livro, uma pintura, enfim, é um objeto que corporifica o capital cultural incorporado. Já o institucionalizado é o conjunto de títulos de educação que o indivíduo possui, ou seja, o certificado, o diploma (STREHLAU, 2008). Hoje, nota-se que as pessoas se preocupam mais com o capital cultural institucionalizado do que com o incorporado. Assim, o aprendizado parece ter papel secundário na busca do título, do diploma. É mais importante ter o diploma do que aprender.

A partir dessa perspectiva de distinção de indivíduos e grupos com base no consumo de bens, Slater (2002, p. 147) comenta que "os bens e os rituais tornam a ordem social tanto visível quanto eficiente: de certo modo, os tipos de consumo são como um mapa da ordem social, com o 
qual é possível identificar as classificações e categorias que a constituem”. Ou seja, o fluxo de bens por meio dos rituais de consumo mapeia e consolida as redes complexas das relações sociais.

\section{RITUAL E SEUS COMPONENTES}

O ritual é um tipo de ação social no qual há manipulação de significado cultural para propósitos de comunicação e categorização coletiva e individual (MCCRACKEN, 2003). Dessa forma, ele é uma poderosa ferramenta de transferência de significado do consumidor para o bem. Rook (2007, p. 83) define ritual nos seguintes termos:

O termo ritual refere-se a um tipo de atividade expressiva e simbólica construída de múltiplos comportamentos que se dão numa sequência fixa e episódica e que tendem a se repetir com o passar do tempo. O comportamento ritual roteirizado é representado dramaticamente e realizado com formalidade, seriedade e intensidade interna.

Para algo ser caracterizado como experiência ritualística, é necessária a verificação de certos elementos. De acordo com o autor, esses seriam quatro: artefatos simbólicos, roteiro, papéis dos agentes e audiência (plateia). Todavia, há o pressuposto para a caracterização de ritual advindo da sua própria definição, que é a repetição.

Os artefatos simbólicos, quando no contexto ritualístico, comunicam mensagens simbólicas específicas que integram o significado da experiência como um todo. Servem, também e mais genericamente, como símbolos rituais na forma mitológica de caracteres, ícones, logomarcas ou cores significativas. Além disso, os artefatos rituais muitas vezes assumem a forma de produtos de consumo que acompanham um ambiente ritual ou são nele consumidos (ROOK, 2007). Como exemplo, pode-se citar a aliança nos casamentos.

Um roteiro do ritual orienta o uso dos diversos materiais artefatuais e prescreve um paradigma de consumo que pode incluir uso extensivo ou relativamente limitado de produtos. Ele identifica não só os artefatos a serem usados, mas também sua sequência comportamental e quem deve usá-los. É nesse sentido que surge o elemento dos papéis dos agentes. Um roteiro de ritual é realizado por pessoas que ocupam diversos papéis rituais. Em um casamento, por exemplo, é sempre o pai que entra com a noiva, e é a noiva que se dirige ao noivo e não o contrário. O quarto elemento refere-se à existência de audiência, ou seja, de outras pessoas, mesmo sendo apenas expectadoras e não participantes do ritual, que o reconheçam como tal.

A repetição, que é o último elemento, trata da recorrência de eventos ao longo do tempo. "Um ritual tende a se realizar da mesma maneira a cada vez que é observado, de maneira que os eventos rituais funcionam como dispositivos mnemônicos que trazem à tona pensamentos e sentimentos específicos no indivíduo" (ROOK, 2007, p. 83). Esses pensamentos e sentimentos são experimentados por todos os envolvidos no ritual, desde a plateia até os atores principais.

Quanto à tipologia dos rituais, o baile de debutante enquadra-se como "rito de passagem" (ESCALAS, 1993). Este é usado para mover o indivíduo de uma categoria cultural de pessoa para outra. Desse modo, um conjunto de simbolismos são abandonados, enquanto outros são 
apropriados (MCCRACKEN, 2003). "Os grandes ritos de passagem, como formaturas e casamentos, marcam importantes transições de status social e estimulam grande envolvimento psicológico e forte ansiedade" (ROOK, 2007, p. 83).

A passagem da infância para a adolescência é marcada pela puberdade física, que nas moças "é marcada pelo entumescimento dos seios, o alargamento da bacia, o aparecimento de pelos no púbis e sobretudo pelo primeiro fluxo menstrual” (GENNEP, 2011, p. 72). Socialmente, a passagem é marcada pelo baile de 15 anos. Como a maioria das meninas tem sua primeira menstruação até os 15 anos, entende-se o porquê de a festa acontecer nessa idade.

\section{ASPECTOS METODOLÓGICOS}

Para o desenvolvimento deste estudo, escolheu-se a metodologia qualitativa, sendo que a pesquisa é exploratória. O corte temporal foi transversal. A população foi delimitada pelos profissionais que trabalham com festas na cidade de Maringá-PR. A técnica de amostragem utilizada foi a não probabilística e o critério de filtragem foi feito a partir dos profissionais que trabalharam em eventos do tipo "festas de 15 anos" nos 2 anos anteriores à coleta dos dados. Escolheu-se esse período para que os eventos estivessem vivos na memória desses profissionais.

Para a coleta de dados, foi feito contato telefônico com um reconhecido salão de festas de Maringá, o que permitiu a indicação de alguns profissionais que organizam festas, conhecidos na região como promoters. Assim, foi feito contato telefônico com os possíveis entrevistados, possibilitando o agendamento de algumas entrevistas. Posteriormente, seguiu-se a técnica bola de neve, que é uma forma de amostra não probabilística, que utiliza cadeias de referência. A execução da amostragem em bola de neve se constrói da seguinte maneira: para o pontapé inicial, lança-se mão de informantes-chaves, nomeados como sementes, a fim de localizar algumas pessoas com o perfil necessário para a pesquisa, dentro da população geral. Em seguida, solicita-se que os sementes indiquem novos contatos com as características desejadas, a partir de sua própria rede pessoal, e assim sucessivamente (VINUTO, 2014). As entrevistas foram realizadas em escritórios e residências dos entrevistados, mediante roteiro semiestruturado, gravadas e, depois, transcritas.

Para tratamento e interpretação dos dados, foi usado o método análise de conteúdo. Bardin (1977) configura a análise de conteúdo como um conjunto de técnicas de análise das comunicações, que utiliza procedimentos sistemáticos e objetivos de descrição do conteúdo das mensagens. Berelson (1984) diz que a análise de conteúdo é uma técnica de pesquisa que busca descrever o conteúdo manifesto de comunicação de maneira objetiva, sistemática e qualitativa. A análise de conteúdo foi auxiliada pelo programa de software de computador QSR NVivo. Este permitiu que o processo de vasculhar cada linha do texto e atribuir códigos (no caso, nós) se tornasse mais rápido e eficiente. Quanto à confiabilidade e validade da pesquisa, foram utilizados os princípios de Creswell (2007): verificação das transcrições e utilização de uma descrição rica e densa para comunicar os resultados. 


\section{ANÁLISE E INTERPRETAÇÃO DOS DADOS}

A pesquisa foi realizada com cinco profissionais maringaenses da área de eventos durante o segundo semestre do ano de 2012. Todos eles acompanharam presencialmente a realização das festas de 15 anos em que atuaram, o que permitia a observação de todo o evento. Cada um, no mínimo, já havia realizado seis festas desse tipo. O Quadro 1 revela o perfil dos entrevistados (a partir de agora, por conveniência, e para garantir o anonimato dos entrevistados, o entrevistado 1 será chamado de E1, o entrevistado 2, de E2, e assim sucessivamente):

Quadro 1. Perfil dos entrevistados.

\begin{tabular}{|lccc|}
\hline ENTREVISTADOS & SEXo & ÁREA & $\begin{array}{c}\text { TEMPO DE TRABALHO } \\
\text { COM FESTAS }\end{array}$ \\
\hline E1 & Masculino & Aluguel de som e luz & 02 anos \\
\hline E2 & Masculino & Fotógrafo & 40 anos \\
\hline E3 & Masculino & Organizador de eventos & 08 anos \\
\hline E4 & Feminino & Organizadora de eventos & 15 anos \\
\hline E5 & Masculino & DJ & 16 anos \\
\hline
\end{tabular}

Fonte: Dados da pesquisa.

Primeiramente, buscou-se a identificação dos componentes da definição de ritual nos discursos dos entrevistados, quais sejam: artefatos simbólicos, roteiro, papéis dos agentes, audiência (plateia) e repetição (ROOK, 2007). Revelando esses componentes, é possível afirmar com segurança que o baile de debutantes é um ritual.

Os nós principais que emergiram da análise de conteúdo foram: 1) artefatos simbólicos, 2) roteiro, 3) audiência, 4) repetição e 5) significado do baile de debutante. Dentro de cada um desses nós, foram separados palavras e trechos dos discursos transcritos dos entrevistados que se identificassem com as características de cada nó encontradas na teoria sobre o assunto. No nó "Roteiro", foi construído o subnó "Papéis dos agentes”. Isso se deu devido a esses dois pressupostos da definição de ritual estarem intimamente ligados e aparecerem frequentemente próximos nos discursos.

No nó "Significado do baile de debutantes", foi construído o subnó "Mudança/ ressignificação da festa". Como o rito de passagem é a principal fonte do ritual estudado, já que o baile de debutante denota a passagem da menina da fase da infância para a adolescência, a mudança desse significado refletiu sobremaneira na análise dos discursos dos entrevistados. Assim, esse subnó foi construído. Outro subnó criado em função da análise mercadológica dos bailes de debutantes foi o "Média de gasto". Dentro deste, foram introduzidos trechos dos discursos dos entrevistados nos quais eles mencionavam a média de gastos na realização da festa de 15 anos.

\section{ARTEFATOS SIMBÓLICOS}

Quanto aos artefatos simbólicos, estes servem como símbolos rituais na forma mitológica de caracteres, ícones, logomarcas ou cores significativas, sendo que muitas vezes assumem a forma de produtos de 
consumo que acompanham um ambiente ritual ou são nele consumidos (ROOK, 2007). Conforme o Quadro 2, pode-se identificar no discurso de cada entrevistado os seguintes artefatos presentes nas festas de 15 anos:

Quadro 2. Identificação dos artefatos simbólicos.

\begin{tabular}{|c|c|}
\hline ENTREVISTADOS & ARTEFATOS SIMBÓLICOS MENCIONADOS \\
\hline E1 & $\begin{array}{l}\text { Pista de dança, telão, TV de plasma, valsa, mesa de frios, jantar, } \\
\text { música, salão. }\end{array}$ \\
\hline E2 & $\begin{array}{l}\text { Fotografias, filmagem, valsa, música, padrinhos, decoração, bolo, } \\
\text { jantar, vestido, salão. }\end{array}$ \\
\hline E3 & $\begin{array}{c}\text { Decoração, salão, bolo, doces, lembrancinhas, telão, TV de plasma, } \\
\text { música, fotografias (book), filmagem (clipe), pista de dança, vestido, } \\
\text { valsa, convite, jantar, mesa de frios, brinde. }\end{array}$ \\
\hline E4 & $\begin{array}{l}15 \text { casais, valsa, padrinhos, música, sapato (troca), vestido, } \\
\text { fotografias, jantar, mesa de frios, filmagem (clipe), joia (presente } \\
\text { do pai), bolo, brinde, atores globais (como padrinhos), doces, } \\
\text { salão, decoração. }\end{array}$ \\
\hline E5 & $\begin{array}{l}\text { Música, telão, pista de dança, TV de plasma, jantar, mesa de } \\
\text { frios, fotografias, vestido, decoração, bolo, filmagem (clipe), joia } \\
\text { (presente), sapato, boneca, padrinhos, } 15 \text { casais, valsa. }\end{array}$ \\
\hline
\end{tabular}

A ordem dos artefatos simbólicos no Quadro 2 segue a sequência em que apareciam no discurso de cada entrevistado. Muitos dos artefatos aparecem no discurso de todos os entrevistados. Com certeza, aqueles que mais chamam a atenção são a música e a valsa. Esses dois itens são citados pelos entrevistados como imprescindíveis para a realização do evento, pois demarcam de forma significativa o cerimonial do baile de debutantes. Nenhum dos entrevistados mencionou alguma festa de 15 anos que não tenha tido a tradicional música e a dança presentes na festa.

Outro ponto importante é a questão de o baile de debutante ser considerado uma festa de aniversário. Dessa maneira, bolo, doces, mesa de frios, jantar, decoração, convite e lembrancinhas podem ser encontrados em qualquer outra festa de aniversário. Todavia, ainda assim exercem forte influência no ritual do evento, já que esses itens possibilitam a concretização do baile de debutantes e sua presença é citada quase que de forma unânime pelos entrevistados.

As fotografias da aniversariante quando mais nova e a filmagem (clipe) são capazes de criar uma sensação de déjà vu, fazendo com que seja possível provocar no organismo uma sensação visceral de como era a menina na infância. Elas estão presentes no baile de debutante pois são itens usados mnemonicamente para criar, armazenar e recuperar um sentido do passado que é fundamental para gerir as identidades dos indivíduos (BELK, 1991).

Alguns artefatos simbólicos citados já não são mais usados nas festas de 15 anos maringaenses com tanta frequência. São eles: padrinhos, 15 casais, troca de sapato, joia ganhada pelos pais, boneca e atores em evidência na época de realização das festas. Isso ocorre, segundo os entrevistados, em decorrência da mudança do significado da festa ao longo dos anos e pela condição financeira dos pais que a patrocinam, uma vez que nos últimos anos houve um aumento da realização de festas de 15 anos por pais de classe média. $O$ baile de debutante é mais 
visto atualmente como uma festa de aniversário especial do que como uma apresentação da menina para a sociedade. Assim, alguns desses itens perderam o significado. Outro ponto importante é o fato de certos elementos serem muitos caros, como é o caso dos atores.

Um dos artefatos citado por quase todos os entrevistados e que tem ainda forte influência na festa é o vestido (o vestido formal para a valsa, normalmente longo, e o menos formal, frequentemente curto, usado antes da valsa e após a abertura da pista). A menina, antes da valsa, troca de vestido, o que simboliza seu crescimento. Os entrevistados citaram que pode haver até duas trocas durante a festa, ou seja, podem ser usados até três vestidos.

Tanto E1 quanto E3 citaram como artefatos simbólicos a TV de plasma e o telão, enquanto que E4 e E5 mencionaram a joia como artefato. É interessante esse fato, já que se pode evidenciar que E1 e E3 têm menos tempo de trabalho em festas do que E4 e E5 (ver Quadro 1). Isso pode sinalizar a evolução do setor de eventos e a mudança do significado da festa. A TV de plasma é uma invenção da última década e, assim, foi introduzida nas festas recentemente. A joia era vista como uma forma de delimitar o amadurecimento da jovem, que passava a ser depositária daquele bem. Como hoje a festa de 15 anos reflete mais o aniversário do que o amadurecimento da debutante, ela perdeu o simbolismo e não é mais tão frequentemente usada.

Importante salientar também que na sociedade do espetáculo atual, na qual a imagem tem grande valor, a TV de plasma e o telão assumem função compartilhada com o vestido, o sapato, a boneca e a joia, já que o papel desses artefatos simbólicos é mostrar as fotos e o clipe com as passagens da vida da aniversariante, demonstrando seu crescimento/amadurecimento. Portanto, a TV de plasma e o telão também podem significar a substituição de um artefato que simbolizava o crescimento da menina (vestido, sapato, boneca, joia) por outro que a tecnologia atual disponibiliza.

\section{ROTEIRO E PAPÉIS DOS AGENTES}

O próximo componente do ritual a ser analisado é o roteiro. Todos os entrevistados disseram que há uma sequência de ações para o evento. E3 menciona:

"É a recepção das pessoas, o cerimonial da dança, o jantar e a abertura da pista.”

Seguindo essa lógica, E4 dispõe detalhadamente a ordem da festa de 15 anos:

"Bom, geralmente tem algumas formas né... mas geralmente a aniversariante recepciona os convidados né, com a primeira roupa, aí junto com os pais, e já vai tirando foto e tal, aí lógico que depende do buffet, vai servir alguma coisa pros convidados, depende do buffet, vai servir só depois do cerimonial, então assim tudo depende do buffet, mas aí quando dá meia-noite que é o tradicional né, mas nem sempre acontece dessa forma, a menina troca de roupa e faz a entrada triunfal que a gente fala dela, pra fazer o início do cerimonial, aí se passa clipes ou antes ou depois dessa entrada, enfim, mas aí geralmente quando tem os 15 casais, entram os 15 casais antes dela, nela entrando, 
aí ela entra, aí ela vai receber o presente do pai que geralmente é uma joia, dança a valsa com o pai, o irmão, o avô, enfim, se tiver os 15 casais, os 15 casais dançam juntos, o bolo entra ou o bolo é trazido, aí canta-se o parabéns, estoura-se a champanhe, e brinda com os convidados.”

Conforme visto nos discursos anteriormente citados e nos dos outros entrevistados, pode-se sintetizar a sequência de ações das festas de 15 anos conforme o esquema a seguir:

Quadro 3. Roteiro das festas de 15 anos.

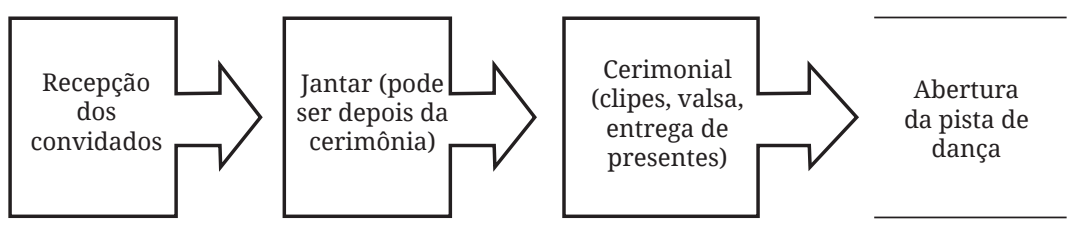

Fonte: Dados da pesquisa.

O roteiro identifica não só os artefatos a serem usados, mas também sua sequência comportamental e quem deve usá-los (ROOK, 2007). Em cada ação do Quadro 3, alguns artefatos citados anteriormente são utilizados. Na recepção, por exemplo, são tiradas fotografias e é quando a menina usa o primeiro vestido da festa.

Ainda dentro de roteiro, é possível identificar um componente de ritual: os papéis dos agentes. No baile de debutantes, existem papéis bem definidos, principalmente no momento da valsa. O pai é quem sempre dança a primeira valsa com a filha. E1 cita:

"eu acho que o mais legal é ver a entrada do pai com ela, eu acho que é o mais bacana.”

Pode-se mencionar também o papel dos 15 casais e dos padrinhos durante o cerimonial. Os casais dançam a valsa em seguida a da debutante com o seu pai. Normalmente são amigos e primos da aniversariante, ou seja, têm a mesma faixa etária dela. A próxima valsa é com os padrinhos. Estes diferem de festa para festa, entre avôs, tios, irmãos, namorados e, como mencionado por E4, atores. Convém lembrar que na hora da recepção dos convidados os pais acompanham a filha.

\section{AUDIÊNCIA}

O próximo componente dos bailes de debutante é a audiência. Os convidados são de suma importância para a realização da festa. Sem eles, é impossível que o evento ocorra. Na hora de cantar o parabéns, na valsa e em todo o cerimonial, é imprescindível que a plateia se envolva e reaja com tudo o que está acontecendo na festa. No discurso de E1, ele menciona uma festa de 15 anos em que na hora da valsa a aniversariante entrou de moto, o que cativou os convidados:

"essa também teve um diferencial [...] uma das entradas dela foi em cima de uma Harley bem barulhenta assim, todo mundo ficou bem agitado...”

Portanto, é evidente a presença e importância da audiência nos bailes de debutante e como esta exerce grande influência no evento. 


\section{REPETIÇÃO}

O último componente a ser identificado nas festas de 15 anos é a repetição. Quando se falou no roteiro, essa questão já ficou clara. Contudo, os discursos dos entrevistados são explícitos nesse sentido, já que todos citam a ideia de tradição, de antigo (no sentido de conservador), de rotina, ou seja, de que a festa de 15 anos já acontece da mesma forma há muito tempo; enfim, que se repete no tempo.

Quadro 4. O componente "Repetição" nos discursos dos entrevistados.

\begin{tabular}{|c|c|}
\hline ENTREVISTADOS & DISCURSO \\
\hline E1 & "É uma coisa tradicional né...que vem desde as antiguidades..." \\
\hline E2 & $\begin{array}{l}\text { "É uma coisa meio tradicional né, ou seja, é uma coisa antiga né as } \\
\text { festas de } 15 \text { anos [...]" }\end{array}$ \\
\hline E3 & $\begin{array}{l}\text { "Houve uma evolução, e isso aí é na área de eventos, não é nem no } \\
\text { ritual, porque a gente mantém a tradição, mas com um outro olhar, } \\
\text { com uma outra cara, mas a área de eventos evoluiu muito." }\end{array}$ \\
\hline E4 & $\begin{array}{c}\text { "[...] eu acredito que não pode faltar isso por causa da tradição, } \\
\text { porque eu ainda prezo pelas festas de } 15 \text { anos em cima de uma } \\
\text { tradição né [...]" }\end{array}$ \\
\hline E5 & $\begin{array}{l}\text { "Ah isso aí geralmente já virou tipo um, como é que eu vou falar pra } \\
\text { você, é uma rotina né, a aniversariante faz } 15 \text { anos [...]" }\end{array}$ \\
\hline
\end{tabular}

Encerra-se, assim, a identificação dos componentes da definição de ritual. Como pode ser observado com a análise e a interpretação dos dados, o baile de debutante possui todos os elementos para ser caracterizado como um ritual e, acima de tudo, como consumo ritualístico, já que os artefatos simbólicos encontrados nas festas de 15 anos são bens de consumo.

\section{SIGNIFICADO DO BAILE DE DEBUTANTE}

Os discursos dos entrevistados demonstraram que o significado da festa é a passagem das meninas da infância para a adolescência. É considerada como um rito de passagem, por isso a valsa e as outras ações simbólicas, como a troca de vestidos e a joia como presente, servem para demonstrar que o pai está assumindo o crescimento da filha para a sociedade. A menina sai da esfera doméstica, na qual se encontrava porque era criança, e entra para a esfera pública, já que agora é uma moça.

$$
\text { “é aquela ideia de que a menina vai virar moça né?” (E1) }
$$

"assim ritualisticamente falando, é uma apresentação, é quando a menina deixa de ser menina e vira mulher, e elas são apresentadas à sociedade [...]” (E3)

O amadurecimento da jovem é o significado da festa desde que surgiu o conceito na Inglaterra, na segunda metade do século XVI. Nessa época, durante o reinado da rainha Elizabeth I, esse amadurecimento era concretizado pelo costume de apresentar formalmente jovens elegíveis ao casamento na corte. Três séculos mais tarde, a rainha Vitória deu 
à cerimônia sua forma atual, com as meninas vestidas de branco e o arco oficial chamado de "reverência". Na época vitoriana, as jovens eram mantidas reclusas em casa até os 18 anos idade, quando era feita sua apresentação à sociedade, o que significava que elas tinham sido formalmente autorizadas a serem vistas em público e com um homem (ESCALAS, 1993).

Mesmo sendo identificado o significado de passagem de fase na vida das aniversariantes, nos dados colhidos os entrevistados mencionaram muito a questão de os bailes de debutantes evidenciarem simbolicamente a riqueza da família e o status social, mais do que uma formalização para a sociedade de que a menina (debutante) estava se tornando moça. Os entrevistados mencionaram que o mínimo para se fazer um baile de debutante é de $\mathrm{R} \$ 15.000,00$ e que já houve festas em que foram gastos $\mathrm{R} \$ 300.000,00$.

"a gente percebe que é muito mais pra fazer uma festa, do que propriamente por causa da tradição que existia antigamente de se apresentar a menina à sociedade, essas coisas nesse sentido.” (E4)

"Status pra sociedade... pros pais... pros pais é um sinônimo de status, eu estou podendo fazer os 15 anos da minha filha tá [...].” (E3)

Nesse sentido, pode-se fazer a ligação com a questão anteriormente vista nesse artigo, de que "as mercadorias são usadas para comunicar e diferenciar socialmente as práticas e estratégias de consumo de diferentes segmentos sociais e suas implicações para a formação de hábitos, identidades e diferenciações” (BARBOSA, 2010, p. 41). Ou seja, se consome para se diferenciar de outros indivíduos, achar sua identidade, ao mesmo tempo em que se consome a fim de se assemelhar a um grupo, uma classe social. Fazendo a festa de 15 anos, tanto os pais quanto a aniversariante buscam o status social, a fim de se identificarem com a classe social à qual pertencem ou que almejam pertencer. Isso justifica a grande indústria de eventos por trás da festa. Vários profissionais trabalham com os bailes, desde costureiras a fotógrafos, e tal fato acontece, sobretudo, devido ao status que a festa denota.

Importante dizer que os profissionais entrevistados mencionam que já fizeram festas de 15 anos de todas as classes sociais. Dessa maneira, não existe somente um público de classe média ou alta que realiza o evento. Todas as classes realizam o baile, com diferenças de gastos, mas sempre com a presença dos artefatos simbólicos mapeados.

Outra questão relevante quanto ao baile de debutante é o paradoxo existente entre o ritual e seu significado. Como verificado, todos os componentes de ritual foram encontrados nos discursos dos entrevistados, ou seja, estes reconhecem a festa de 15 anos dessa forma. No entanto, muitos mencionam que é uma festa de aniversário, o que denota que o significado de apresentar a debutante para a sociedade se perdeu no tempo. Na realidade, houve uma ressignificação da festa em decorrência de uma mudança social, na qual as jovens possuem liberdade de transitar em eventos sociais mesmo antes dos 15 anos. Além disso, atualmente elas assumem outros papéis, como o de profissionais, ou seja, o casamento não é mais o fim primordial do baile - tanto que o matrimônio hoje é postergado para a casa dos 20 ou 30 anos.

Com isso, é possível compreender o paradoxo a partir de Bourdieu (1973) e do capital cultural: há maior preocupação no capital cultural 
objetivado e institucionalizado, ou seja, na presença de todos os artefatos simbólicos, do que no capital cultural incorporado, que simboliza o reconhecimento do significado da festa e o entendimento do porquê de todo aquele ritual. Os artefatos simbólicos são simplesmente consumidos sem se levar em consideração a significação de todo aquele cerimonial existente nos bailes de debutantes. A sociedade atual sabe que existe o ritual e o que deve constituí-lo, já que o replica inúmeras vezes; no entanto, não consegue reconhecer o que tudo simboliza. Nesse ínterim, nota-se que a festa que antes tinha o intuito de apresentar a jovem à sociedade, tendo como fim um bom casamento, hoje permite que a jovem amplie seu círculo social e, consequentemente, sua rede de contatos, o que pode favorecer futuramente tanto nos seus relacionamentos afetivos quanto nos profissionais ou de qualquer outra natureza. A mudança primordial na vida das jovens após o baile é o aumento de sua network. Isso acontece porque nos bailes de debutante os pais costumam convidar seu círculo de amigos e parentes mais extenso, incluindo parentes mais distantes e conhecidos.

\section{CONSIDERAÇÕES FINAIS}

A festa de 15 anos pode ser compreendida como um consumo ritualístico, já que os artefatos rituais presentes nos bailes de debutante assumem a forma de produtos de consumo que acompanham o ambiente ritual ou são nele consumidos (ROOK, 2007). Como prova disso, nessas são gastas vultuosas quantias pelos pais, que patrocinam o evento. Devido aos altos gastos, a festa de 15 anos simboliza riqueza da família e status social.

Apesar da sociedade atual reconhecer a festa de 15 anos como um rito de passagem, ela não reconhece o significado do simbolismo presente em todos os artefatos consumidos na festa da mesma forma como estes eram reconhecidos em outras épocas, nas quais o principal objetivo das moças era o de se casar. Assim, os entrevistados mencionam que hoje se faz a festa mais por ostentação e tradição. Essa é a grande questão da sociedade de consumo atual. Consome-se para se diferenciar de outros indivíduos, ao mesmo tempo em que se consome a fim de se assemelhar a um grupo, a uma classe social. Os significados de status e pertencimento de classe estão estritamente ligados ao consumo e são considerados tão importantes nas sociedades capitalistas que levam os indivíduos, muitas vezes, a não refletirem ou se questionarem do porquê de certos consumos. Assim, pais gastam vultosas somas na aquisição, por exemplo, de dois vestidos para a debutante, para teoricamente simbolizar que esta, quando troca o vestido curto pelo longo, está informando para a audiência que deixou a infância e se tornou uma jovem mulher, com todas as responsabilidades que isso implica. Na prática atual, essa transição na vida da aniversariante irá ocorrer anos depois. No fim, o que o baile permite é a ampliação da rede social das jovens, e não mais a busca por um bom casamento.

Sugere-se para futuras pesquisas a investigação do significado de outros tipos de rito de passagem presentes na sociedade moderna, como o casamento ou os bailes de formatura. Como limitação do presente estudo, pode-se indicar a coleta de dados apenas com profissionais da área e não com debutantes ou seus pais, bem como a pesquisa ter sido feita somente na cidade de Maringá, no estado do Paraná. 


\section{REFERÊNCIAS}

BARBOSA, L. Sociedade de consumo. Rio de Janeiro: Jorge Zahar, 2010.

BARDIN L. Análise de conteúdo. Lisboa: Edições 70, 1977.

BELK, R. W. Possessions and the sense of past. SV - Highways and byways: naturalistic research from the consumer behavior odyssey, Provo, p. 114-130, 1991.

BERELSON, B. Content analysis in communication research. New York: Hafner; 1984

BOURDIEU, P. A economia das trocas simbólicas. São Paulo: Perspectiva, 1973.

COLETO, L. Pesquisa revela que paranaense solteiro casa mais cedo. Tribuna Paraná, Curitiba, 26 nov. 2009. Disponível em: <https://goo.gl/tgixvg>. Acesso em: 19 jul. 2017

CRESWELL, J. W. Projeto de pesquisa: métodos qualitativo, quantitativo e misto. 2. ed. Porto Alegre: Artmed, 2007.

CUPOLIO, M. B. N.; CASOTTI, L. M.; CAMPOS, R. D. Estudos de consumo: um convite para a riqueza e para a simplicidade da pesquisa de rituais brasileiros. Revista ADM.MADE, Rio de Janeiro, v. 17, n. 3, p. 27-46, set./dez. 2013.

ESCALAS, J. E. The consumption of insignificant rituals: a look at debutante balls. NA: advances in consumer research, Provo, v. 20, p. 709-716, 1993.

GARCIA, W. Consumo e diversidade cultural/sexual: investigações interdisciplinares. Signos do consumo, São Paulo, v. 1, n. 2, p. 214-225, 2009.

GUILLEN, F. Maringá é a segunda cidade do Paraná com mais famílias nas classes A e B. Gazeta do Povo, Curitiba, 31 jan. 2012. Caderno Economia. Disponível em: <https://goo.gl/ mFilos>. Acesso em: 19 jul. 2017.

GENNEP, A. V. Os ritos de passagem. Petrópolis: Vozes, 2011.

MCCRACKEN, G. Cultura e consumo: novas abordagens ao caráter simbólico dos bens e das atividades de consumo. Tradução Fernanda Eugenio. Rio de Janeiro: Mauad, 2003.

ROOK, D. W. Dimensão cultural do comportamento de Consumo. RAE: Revista de administração de empresas, São Paulo, v. 47, n. 1, p. 81-98, 2007.

SASSATELLI, R. Consumer culture: history, theory and politics. New York: Sage, 2007.

SLATER, D. Cultura e consumo e modernidade. São Paulo: Nobel, 2002.

STREHLAU, S. Marketing do luxo. São Paulo: Cengage Learning, 2008.

TEIXEIRA, W. O perfil do consumidor maringaense. O Diário.com, Londrina, 25 set. 2013. Disponível em: <https://goo.gl/PPnmzn>. Acesso em: 20 jul. 2017.

TETREAULT, M. A. S.; KLEINE III, R. E. Ritual, ritualized behavior, and habit: refinements and extensions of the consumption ritual construct. NA: advances in consumer research, Provo, v. 17, p. 31-38, 1990.

TRINDADE, E. et al. A práxis enunciativa na publicidade contemporânea: a tensão entre permanência e fugacidade nos rituais de compra, uso e posse. Signos do Consumo, São Paulo, v. 3, n. 1, p. 106-123, 2011.

VINUTO, J. A amostragem em bola de neve na pesquisa qualitativa: um debate em aberto. Temáticas, Campinas, v. 22, n. 44, p. 203-220, ago./dez. 2014. 